\title{
Dual mechanisms governing reward-driven perceptual
}

\section{learning [version 1; peer review: 2 approved]}

\author{
Dongho Kim ${ }^{1,2}$, Sam Ling ${ }^{1-3}$, Takeo Watanabe
}

${ }^{1}$ Department of Psychological and Brain Sciences, Boston University, Boston, MA, USA

${ }^{2}$ Center for Computational Neuroscience and Neural Technology, Boston University, Boston, MA, USA

${ }^{3}$ Donders Institute for Brain, Cognition and Behavior, Radboud University, Nijmegen, The Netherlands

${ }^{4}$ Department of Cognitive, Linguistic, and Psychological Sciences, Brown University, Providence, RI, USA

V1 First published: 10 Sep 2015, 4:764

https://doi.org/10.12688/f1000research.6853.1

Latest published: 10 Sep 2015, 4:764

https://doi.org/10.12688/f1000research.6853.1

\section{Abstract}

In this review, we explore how reward signals shape perceptual learning in animals and humans. Perceptual learning is the wellestablished phenomenon by which extensive practice elicits selective improvement in one's perceptual discrimination of basic visual features, such as oriented lines or moving stimuli. While perceptual learning has long been thought to rely on 'top-down' processes, such as attention and decision-making, a wave of recent findings suggests that these higher-level processes are, in fact, not necessary. Rather, these recent findings indicate that reward signals alone, in the absence of the contribution of higher-level cognitive processes, are sufficient to drive the benefits of perceptual learning. Here, we will review the literature tying reward signals to perceptual learning. Based on these findings, we propose dual underlying mechanisms that give rise to perceptual learning: one mechanism that operates 'automatically' and is tied directly to reward signals, and another mechanism that involves more 'top-down', goaldirected computations.

Keywords

Perceptual learning , Vision, Reward, goal-directed, contingency , temporal contiguity, automatic , task-irrelevant

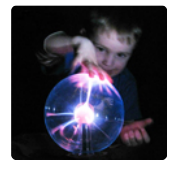

This article is included in the Active learning and decision making collection.

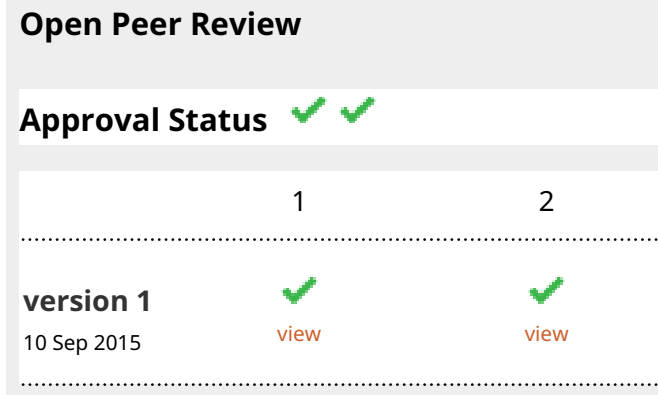

1. Wim Vanduffel, Massachusetts General Hospital, Charlestown, USA

2. Leonardo Chelazzi, University of Verona, Verona, Italy

Any reports and responses or comments on the article can be found at the end of the article. 
Corresponding author: Takeo Watanabe (takeo_watanabe@brown.edu)

Competing interests: No competing interests were disclosed.

Grant information: This study was supported by NIH grant number R01 EY015980.

The funders had no role in study design, data collection and analysis, decision to publish, or preparation of the manuscript.

Copyright: ( $\subset 2015 \mathrm{Kim}$ D et al. This is an open access article distributed under the terms of the Creative Commons Attribution License, which permits unrestricted use, distribution, and reproduction in any medium, provided the original work is properly cited.

How to cite this article: Kim D, Ling $S$ and Watanabe T. Dual mechanisms governing reward-driven perceptual learning [version 1; peer review: 2 approved] F1000Research 2015, 4:764 https://doi.org/10.12688/f1000research.6853.1

First published: 10 Sep 2015, 4:764 https://doi.org/10.12688/f1000research.6853.1 


\section{Introduction}

Perceptual learning is the process by which sensory systems in humans or animals improve their ability to perform a perceptual task, often after extensive experience with a particular stimulus. It had long been believed that this type of learning was tied to one's task performance on that stimulus. Support for this came from a number of studies that found benefits of perceptual learning for features that were relevant to a task, whereas features that were merely exposed showed little-to-no learning ${ }^{1-3}$. Taken together, these studies supported the hypothesis that conscious effort directed toward a sensory feature, by means of processes such as attention, is necessary for the feature to be learned ${ }^{2-4}$.

In recent years, however, evidence for a new type of perceptual learning has emerged - one that may not necessitate higher-level, goal-directed processes, such as attention ${ }^{5-14}$. In a study by Watanabe et al. (2001), evidence was found that perceptual learning could transpire outside of the window of attention. Specifically, observers were asked to perform a demanding task at the center of a display, while they were exposed to an array of moving dots presented in the periphery. Importantly, only $5 \%$ of the dots moved coherently in a fixed direction, while the remaining dots moved randomly. Because the motion signal was task-irrelevant, it was assumed that little-to-no attention was actively deployed to that stimulus. Moreover, sensitivities to the $5 \%$ and $10 \%$ coherent motion were measured before (pre-test) and after (post-test) a training period. The strength of the $5 \%$ coherent motion was so weak that subjects were not able to discriminate or detect the coherent motion direction above chance, either at the pre-test or the post-test. Nevertheless, the result of the post-test revealed that repeated exposure improved sensitivity for the $10 \%$ coherent motion in the exposed direction. The authors interpreted these results as evidence for a new type of perceptual learning, coined 'task-irrelevant perceptual learning', which occurs without attention ${ }^{5-7}$.

Is mere task-irrelevant exposure to a stimulus truly sufficient for perceptual learning? A follow-up study demonstrated that mere exposure is, in fact, insufficient; performance benefits of exposure only occurred when there was a temporal pairing between a taskirrelevant motion signal and task-relevant targets ${ }^{9}$. Most interestingly, task-irrelevant learning appeared to only occur in instances in which the target was successfully recognized ${ }^{15}$. Why is that? One interpretation is that successful recognition of the target letter led to a sense of accomplishment for the participant, which elicited an internal reward signal. As a consequence, task-irrelevant perceptual learning may arise as a result of repeated pairing between a stimulus and internal reward signals, which are released diffusively throughout the brain, affecting both task-relevant and task irrelevant stimuli 5 .

Although the aforementioned studies did not explicitly test this reward-based hypothesis, a number of studies have since emerged, derived from work in animal models and humans, supporting the hypothesis that reward signals are sufficient in order for perceptual learning to manifest. In this article, we will review and synthesize work that has examined how reward signals play a role in shaping perceptual learning. Many models in cognition assume that goal-directed behavior plays a dominant role in governing learning. Goal-directed behavior is a class of behavior aimed towards completion of a task - a subset of self-attributed motives commonly assumed to require high-level cognitive processes, such as attention and decision-making. For instance, a classic example of a goal-directed behavior is the online computation of the probabilistic contingency between the presence of a stimulus, and receiving a reward. In phenomena such as reward-driven perceptual learning, an individual's estimation of the 'contingency' between rewards and visual stimuli has been shown to impact learning rates, clearly indicating that goal-directed processes are involved. However, not all behaviors necessarily tap into these high-level processes. For instance, reward-driven perceptual learning has also been shown to occur in the absence of any task, as well as outside of an individual's awareness. Interestingly, this suggests that reward signals can gate the emergence of learning, untainted by other higher-level cognitive processes. To explain these results, we propose dual underlying mechanisms of reward-driven perceptual learning: one mechanism that operates 'automatically', free from goal-directed processes, and another mechanism that involves more 'top-down', goal-directed computations, and requires conscious estimation of learning contingencies. Moreover, we propose that perceptual learning, in combination with paradigms used to suppress images from visual awareness, can be leveraged as tools to probe this more 'automatic' component of learning.

\section{How do rewards shape perceptual learning, independent of goal-directed processes?}

The reward-driven hypothesis for task-irrelevant perceptual learning is based on the assumption that internal reward signals are released when subjects successfully recognize a target item, with the temporal pairing between a task-irrelevant feature and the reward signals playing a crucial role in determining task-irrelevant perceptual learning. However, it is possible that the task-based component in those aforementioned studies is unnecessary, and that it truly is the reward signal itself that triggers task-irrelevant perceptual learning. How does one test this hypothesis? The lion's share of perceptual learning studies employ a training procedure by which observers perform a task that is the same or similar to evaluating the amount of learning. However, this makes it difficult to truly understand the effects of reward on perceptual learning, because the role of rewards in such paradigms is necessarily entangled with higher-level cognitive processes, such as attention and goal-directed decision-making, when participants are consciously performing a task on a stimulus. In order to truly understand how rewards gate perceptual learning, one should empirically disentangle rewards process from other cognitive processes. Classical conditioning is a process by which learning is acquired through repeated pairings of a stimulus and a reinforcer ${ }^{16}$. Interestingly, classical conditioning does not necessitate any task during conditioning. Therefore, by leveraging classical conditioning, one can gain a true understanding of how reward signals modulate perceptual learning, untainted by goal-directed decision processes.

In a definitive test of the reward-signal hypothesis for perceptual learning, Seitz, Kim \& Watanabe (2009) discovered that perceptual learning could occur even without any task involvement whatsoever. 
To do so, this study used a classical conditioning procedure in which human subjects, who were deprived of food and water, passively viewed visual stimuli while receiving occasional drops of water as rewards ${ }^{17-19}$. To ensure that perceptual learning was driven purely by reward signals, this study used a technique known as continuous flash suppression ${ }^{20}$ throughout the training regime, which is known to render visual stimuli imperceptible. Surprisingly, learning occurred through stimulus-reward pairing in the absence of a task and without awareness of the stimulus presentation. Since neither task nor attention was involved during the training procedure, these results study strongly implicate the continuous temporal pairing between stimulus feature and reward signals as being the necessary and sufficient elements needed for perceptual learning at least in some conditions to occur.

\section{How do rewards shape perceptual learning, in the presence of goal-directed processes?}

While reward signals alone appear to be sufficient to trigger perceptual learning ${ }^{10}$, this result does not preclude goal-directed, conscious behavior from also playing a modulatory role in perceptual learning. According to the theory of motivation, implicit motives represent a more primitive motivational system derived from affective experiences ${ }^{21}$, and it is likely that the task-irrelevant perceptual learning that has been observed rides on this motivational system to yield its effects. However, behavior is also driven by selfattributed (or explicit) motives, which are based on more cognitively elaborated constructs. Such goal-directed behavior, which requires higher-level cognitive processes, likely also governs perceptual learning. Indeed, it has long been suggested that such higher-level cognitive processes, such as attention and/or decision making, also act as main factors in driving perceptual learning ${ }^{1,22-25}$.

What roles, then, do goal-directed behaviors play in perceptual learning? Specifically, do reward signals and goal-directed decision processes elicit a similar pattern of effects on perceptual learning? To examine the similarity between these 'automatic' and 'top-down' processes in perceptual learning, a recent study developed a methodology that combines perceptual learning with a novel training procedure, which employs either classical conditioning or operant conditioning. In the classical conditioning variant of the study, human subjects, who were deprived of food and water, passively viewed visual stimuli while receiving liquid rewards during a 'training regime'10,17-19. This experiment was similar to the aforementioned study ${ }^{10}$, with the notable exception being that there were various reward-contingencies at play, with the orientation content of a visual stimulus paired with a certain probability of receiving a liquid reward ${ }^{26}$. To vary the probability of reward-delivery, three different stimulus orientations were used for each subject: 1) the zero-contingency orientation had a reward-probability equal to the background reward-rate of $50 \%, 2$ ) the positive-contingency orientation had an $80 \%$ probability of reward, and 3) the negativecontingency orientation had a $20 \%$ probability of reward. In the operant conditioning variant of the study, a goal-directed behavior component was added ${ }^{27}$. In contrast to the classical conditioning variant of the experiment, here subjects performed a 'go/no-go task' in response to the orientation stimuli during a training regime. Specifically, if subjects pressed a spacebar, a liquid reward was delivered at a probability contingent on the orientation of that presented stimulus (for example, $80 \%$ for a stimulus tilted $135^{\circ}, 50 \%$ for a stimulus oriented $75^{\circ}$, and $20 \%$ for a stimulus oriented $15^{\circ}$ ).

Results from the classical conditioning variant of perceptual learning showed that learning occurred for both the positive-contingency orientation stimulus as well as the zero-contingency orientation stimulus, but no significant change was found for the negativecontingency orientation stimulus. In contrast, results of the operant conditioning variant of perceptual learning revealed that learning only occurred for the positive-contingency orientation, with no learning found for either the zero-contingency orientation or the negative-contingency orientation ${ }^{27}$. These results suggest that reward-driven perceptual learning without goal-directed processing is distinct from reward-driven perceptual learning with goaldirected processes.

When there is no goal-directed behavior, a consistent pairing between a visual stimulus and reward seems to be the underlying mechanism for perceptual learning to occur ${ }^{5,9,10,28}$. In that case, "temporal contiguity" between rewards and visual stimuli play a crucial role for perceptual learning to occur ${ }^{5,16}$. However, if goaldirected processes are involved, contingency information between rewards and visual stimuli overrides pure temporal contiguity. In other words, the top-down component can override the automatic components of reward-driven perceptual learning. The operant conditioning variant of perceptual learning demonstrated that learning of a visual stimulus occurred only when that visual stimulus informatively predicted the upcoming rewards ${ }^{29-32}$.

These results square with a study by Law and Gold (2009), where monkeys carried out a goal-directed behavior, performing a visual task to receive rewards. In that study, connections between sensory neurons and the goal-directed decision process that interprets the sensory information were first modified by reward driven reinforcement signals. Subsequently, that same mechanism acted to further refine these connections to more strongly weight inputs from the most relevant sensory neurons, thereby improving perceptual sensitivity.

\section{Common mechanisms between perceptual learning and conditioning}

Conditioning is the form of learning in which repeated pairings of arbitrary features with rewards or punishments leads to a representation of the rewards or punishment evoked by the paired features $^{29,33}$. At face value, this resembles the task-irrelevant perceptual learning revealed in Seitz and Watanabe (2003), which occurred only when the visual feature was paired with the presentation of a rewarded target. A number of subsequent studies have demonstrated that task-irrelevant perceptual learning in humans can occur for visual stimuli that are consistently paired with internal or external rewards $s^{5,9,10,28}$, and this connection holds true for animal models as well ${ }^{34,35}$. Taken together, these studies suggest common mechanisms shared between conditioning and perceptual learning.

How generalizable are the rules governing conditioning to the domain of perceptual learning? One common theme to the perceptual learning and conditioning literatures is that of contingency ${ }^{29,31,36}$. 
Excitatory conditioning occurs when the probability of a reward is higher for a conditioned stimulus than at other times, which is referred to as positive contingency. Likewise, when the probability is lower (negative contingency), negative conditioning occurs $^{29,31,32,37}$. Since the contingency rule is a hallmark of conditioning, along with contiguity and prediction error ${ }^{29}$, a question arises as to whether perceptual learning follows the same rules of contingency as found in conditioning. Were that the case, then one would expect to observe positive learning, negative learning, or no learning in accordance with the contingency between the predicted signal and the reward. Perceptual learning appears to be governed by both classical and operant conditions principles, depending on the situation. Under a task that promotes high-level processing of the stimulus-reward structure, perceptual learning mirrored the rules of operant conditioning, occurring only for the positive-contingency orientation, with no learning in either the zerocontingency orientation or the negative-contingency orientation ${ }^{27}$. However, under a task that prevented high-level processing of the contingency structure, the effects of perceptual learning much more closely resembled learning of the 'temporal contiguity' between visual features and rewards in classical conditioning, with learning transfer occurring not only for the positive-contingency stimuli, but also for zero-contingency stimuli (of note, there were 50\% stimulirewards pairings in zero-contingency stimuli). Although there has been considerable debate in regards to whether classical conditioning depends on a contingent relation between conditioned stimulus and unconditioned stimulus ${ }^{38}$, perceptual learning under a task that prevented high-level processing of the contingency structure is more closely aligned with classical conditioning, in which learning is more influenced by contiguity than contingency ${ }^{39}$.

\section{Conclusion}

Perceptual learning can occur in the absence of a task and outside the window of awareness, suggesting that reward signals gate the occurrence of perceptual learning. This may emerge through mechanisms akin to classical conditioning, impinging on very early visual sensitivity. In that case, 'temporal contiguity' between rewards and visual stimuli plays a crucial role ${ }^{5,16}$. However, when goal-directed processes are introduced, the contingency between rewards and visual stimuli overrides classical condition-like operations, instead influencing perceptual learning based on the stimulusreward contingencies. This suggests that there exists two underlying mechanisms that give rise to perceptual learning: one mechanism that operates 'automatically' and is tied directly to reward signals, and another overriding mechanism that involves 'top-down', goal-directed computations.

\section{Author contributions}

All authors contributed ideas, text, and critique, and have agreed to the final content.

\section{Competing interests}

No competing interests were disclosed.

\section{Grant information}

This study was supported by NIH grant number R01 EY015980.

I confirm that the funders had no role in study design, data collection and analysis, decision to publish, or preparation of the manuscript.
1. Ahissar M, Hochstein S: Attentional control of early perceptual learning. Proc Natl Acad Sci U S A. 1993; 90(12): 5718-22. PubMed Abstract | Publisher Full Text | Free Full Text

2. Schoups A, Vogels R, Qian N, et al.: Practising orientation identification improves orientation coding in V1 neurons. Nature. 2001; 412(6846): 549-53. PubMed Abstract | Publisher Full Text

3. Shiu LP, Pashler $\mathrm{H}$ : Improvement in line orientation discrimination is retinally local but dependent on cognitive set. Percept Psychophys. 1992; 52(5): 582-8. PubMed Abstract | Publisher Full Text

4. Ahissar M, Hochstein S: The reverse hierarchy theory of visual perceptual learning. Trends Cogn Sci. 2004; 8(10): 457-64.

PubMed Abstract | Publisher Full Text

5. Seitz AR, Watanabe T: A unified model for perceptual learning. Trends Cogn Sci. 2005; 9(7): 329-34.

PubMed Abstract | Publisher Full Text

6. Sagi D: Perceptual learning in Vision Research. Vision Res. 2011; 51(13): 1552-66.

PubMed Abstract | Publisher Full Text

7. Sasaki $Y$, Nanez JE, Watanabe $T$ : Advances in visual perceptual learning and plasticity. Nat Rev Neurosci. 2010; 11(1): 53-60. PubMed Abstract | Publisher Full Text | Free Full Text

8. Gutnisky DA, Hansen BJ, Iliescu BF, et al:: Attention alters visual plasticity during exposure-based learning. Curr Biol. Elsevier Ltd; 2009; 19(7): 555-60. PubMed Abstract | Publisher Full Text

9. Seitz AR, Watanabe T: Psychophysics: Is subliminal learning really passive?
Nature. 2003; 422(6927): 36

PubMed Abstract | Publisher Full Text

10. Seitz AR, Kim D, Watanabe T: Rewards evoke learning of unconsciously processed visual stimuli in adult humans. Neuron. 2009; 61(5): 700-7. PubMed Abstract | Publisher Full Text | Free Full Text

11. Leclercq V, Seitz AR: Fast-TIPL occurs for salient images without a memorization requirement in men but not in women. Baker $\mathrm{Cl}$, editor. PLoS One. 2012; 7(4): e36228. PubMed Abstract | Publisher Full Text | Free Full Text
Pul

12. Leclercq V, Le Dantec CC, Seitz AR: Encoding of episodic information through fast task-irrelevant perceptual learning. Vision Res. 2014; 99: 5-11. PubMed Abstract | Publisher Full Text

13. Beste C, Dinse HR: Learning without training. Curr Biol. 2013; 23(11): R489-99. PubMed Abstract | Publisher Full Text

14. Arsenault JT, Nelissen K, Jarraya B, et al:: Dopaminergic reward signals selectively decrease fMRI activity in primate visual cortex. Neuron. 2013; 77(6): 1174-86.

PubMed Abstract | Publisher Full Text | Free Full Text

15. Seitz AR, Lefebvre $\mathrm{C}$, Watanabe $\mathrm{T}$, et al.: Requirement for high-level processing in subliminal learning. Curr Biol. 2005; 15(18): R753-5. PubMed Abstract | Publisher Full Text

16. Mackintosh NJ: Conditioning and associative learning. Clarendon Press, Oxford, $1983 ; 1$.

Reference Source

17. Dorris MC, Glimcher PW: Activity in posterior parietal cortex is correlated 
with the relative subjective desirability of action. Neuron. $2004 ; 44(2)$ : 365-78. PubMed Abstract | Publisher Full Text

18. Lauwereyns J, Watanabe $\mathrm{K}$, Coe $\mathrm{B}$, et al.: A neural correlate of response bias in monkey caudate nucleus. Nature. 2002; 418(6896): 413-7.

PubMed Abstract | Publisher Full Text

19. Leon MI, Shadlen MN: Effect of expected reward magnitude on the response of neurons in the dorsolateral prefrontal cortex of the macaque. Neuron. 1999; 24(2): 415-25.

PubMed Abstract | Publisher Full Text

20. Tsuchiya N, Koch C: Continuous flash suppression reduces negative afterimages. Nat Neurosci. 2005; 8(8): 1096-101. PubMed Abstract | Publisher Full Text

21. McClelland DC, Koestner R, Weinberger J: How do self-attributed and implicit motives differ? Psychol Rev. 1989; 96(4): 690-702. Publisher Full Text

22. Kahnt T, Grueschow M, Speck O, et al:: Perceptual learning and decision-making in human medial frontal cortex. Neuron. 2011; 70(3): 549-59. PubMed Abstract | Publisher Full Text

23. Xiao LQ, Zhang JY, Wang R, et al.: Complete transfer of perceptual learning across retinal locations enabled by double training. Curr Biol. Elsevier Ltd; 2008; 18(24): 1922-6.

PubMed Abstract | Publisher Full Text | Free Full Text

24. Wang R, Zhang JY, Klein SA, et al:: Task relevancy and demand modulate double-training enabled transfer of perceptual learning. Vision Res. 2012; 61: double.

PubMed Abstract | Publisher Full Text | Free Full Text

25. Zhang JY, Zhang GL, Xiao LQ, et al.: Rule-based learning explains visual perceptual learning and its specificity and transfer. J Neurosci. 2010; 30(37): 12323-8.

PubMed Abstract | Publisher Full Text | Free Full Text

26. Kim $\mathrm{D}$, Watanabe $\mathrm{T}$ : Different properties between reward-driven exposure-based and reward-driven task involved perceptual learning. J Vis. 2010; 10(7): 1112 Publisher Full Text

27. Kim D, Seitz AR, Watanabe T: Visual perceptual learning by operant conditioning training follows rules of contingency. Vis cogn. 2015; 23(1-2): 147-60.

PubMed Abstract | Publisher Full Text | Free Full Text
28. Watanabe T, Náñez JE, Sasaki Y: Perceptual learning without perception. Nature. 2001; 413(6858): 844-8. PubMed Abstract | Publisher Full Text

29. Schultz W: Behavioral theories and the neurophysiology of reward. Annu Rev Psychol. 2006; 57: 87-115.

PubMed Abstract | Publisher Full Text

30. Shannon C: A mathematical theory of communication. Bell Syst Tech J. 1948; 27(3): 379-423 \& 623-656 Publisher Full Text

31. Rescorla RA: Probability of shock in the presence and absence of CS in fear conditioning. J Comp Physiol Psychol. 1968; 66(1): 1-5.

PubMed Abstract | Publisher Full Text

32. Rescorla RA: Behavioral studies of Pavlovian conditioning. Annu Rev Neurosci. 1988; 11: 329-52.

PubMed Abstract | Publisher Full Text

33. Wasserman EA, Miller RR: What's elementary about associative learning? Annu Rev Psychol. 1997; 48: 573-607. PubMed Abstract | Publisher Full Text

34. Law CT, Gold JI: Neural correlates of perceptual learning in a sensory-motor, but not a sensory, cortical area. Nat Neurosci. 2008; 11(4): 505-13. PubMed Abstract | Publisher Full Text | Free Full Text

35. Law CT, Gold Jl: Reinforcement learning can account for associative and perceptual learning on a visual-decision task. Nat Neurosci. Nature Publishing Group; 2009; 12(5): 655-63.

PubMed Abstract | Publisher Full Text | Free Full Text

36. Schultz W, Dayan P, Montague PR: A neural substrate of prediction and reward. Science. 1997; 275(5306): 1593-9.

PubMed Abstract | Publisher Full Text

37. Rescorla RA: Pavlovian conditioning: It's not what you think it is. Am Psychol. American Psychological Association. 1988; 43(3): 151-60. PubMed Abstract | Publisher Full Tex

38. Papini MR, Bitterman ME: The role of contingency in classical conditioning Psychol Rev. 1990; 97(3): 396-403. PubMed Abstract | Publisher Full Text

39. Mackintosh N: A theory of attention: Variations in the associability of stimul with reinforcement. Psychol Rev. 1975; 82: 276-98. Publisher Full Text 


\title{
Open Peer Review
}

\section{Current Peer Review Status:}

\author{
Version 1
}

Reviewer Report 26 October 2015

https://doi.org/10.5256/f1000research.7372.r10916

(C) 2015 Chelazzi L. This is an open access peer review report distributed under the terms of the Creative Commons Attribution License, which permits unrestricted use, distribution, and reproduction in any medium, provided the original work is properly cited.

\section{Leonardo Chelazzi}

Department of Neurological and Movement Sciences, University of Verona, Verona, Italy

I have greatly enjoyed reading this engaging and inspiring review article. The authors of the article provide a concise and highly focused review of the recent literature on visual perceptual learning, and notably of the so-called task-irrelevant perceptual learning (TIPL). The main thrust of the article is to draw a distinction between an automatic form of TIPL, whereby the repeated occurrence of reward in close temporal contiguity with a visual stimulus (feature) determines perceptual learning of that stimulus (feature), and a more complex and cognitively demanding form of perceptual learning, whereby perceptual learning occurs as a result of the task-dependent contingency between a given stimulus (feature) and reward.

I find this dichotomous view of perceptual learning, and of its modulation by reward, especially captivating and important, especially because we have recently elaborated a similar distinction between types of reward-dependent learning in the attentional domain that conform to classical conditioning and types that conform to operant conditioning (Chelazzi et al., 2013). Similar to what elaborated here, in prior studies (Della Libera et al., 2011) we could detect an impact of reward on attentional learning that conformed to classical conditioning using task variants in which participants were led to believe that rewards were received independently of their performance, in a lottery-like fashion. Conversely, in other work (Della Libera \& Chelazzi, 2009) we could detect an impact of reward on attentional learning that conformed to operant conditioning using task variants in which participants were led to believe that rewards received in relation to specific stimuli depended on their attentional performance towards the same stimuli. I actually encourage the authors to note such remarkable consistency between notions that are being developed within the domain of perceptual learning and similar notions that are being developed within the domain of attentional learning. In this regard, it is important to eliminate any potential confusion. Perceptual learning refers to improvements in perceptual performance (increased sensitivity) in relation to specific stimuli (features) as a result of prolonged practice with/exposure to the stimuli (features). In contrast, attentional learning refers to an increase in the efficiency with which participants are able to select, or sometimes ignore, specific stimuli within multi-elements displays. It might well be the case that the two learning phenomena are intimately related, but such a possibility has never been formally tested, at least to the best of my knowledge. 
One aspect that the authors of the present article might want to elaborate on further is the way in which they conceive the task goal-dependency of the perceptual learning effects necessitating top-down control. In operant conditioning, the key link between a given stimulus and reward is the behavioral response directed towards the stimulus. Reward can only be obtained to the extent that an instrumental response is produced towards the stimulus. Any contingency between the stimulus and reward is not sufficient to elicit operant conditioning. In keeping with this notion, in our own work (Chelazzi et al., 2013) we have proposed that in the operant conditioning-like context, the cognitive system is shaped by reward in such a way that particular attentional operations (either selection or suppression, which, in different terms, can be named prioritization or deprioritization) are reinforced in relation to specific stimuli. In this perspective, what is being learned is a specific cognitive act in relation to a given stimulus and the learning is guided by the reward contingency.

As a further development of the distinction put forward by the authors, I suggest that most likely the two forms of perceptual learning ought to differ in other important ways, including the resistance to extinction, the level of generalization across stimuli and tasks, and so forth.

One other aspect that the authors might want to consider is the extent to which the taskdependency of what they describe as the second and more complex form of perceptual learning actually requires that top-down control is exerted in relation to the stimulus for which learning is measured or whether for this type of learning to occur it is sufficient that top-down control is exerted in relation to any stimulus, not necessarily the one for which learning is measured. In the latter scenario, top-down control is engaged, though it is not directed towards the stimulus for which learning is measured, performance monitoring processes are at work, and any resulting reward is linked to ongoing performance. I suppose that this level of top-down control may be sufficient for the second type of perceptual learning to materialize.

Finally, Title and abstract are perfectly adequate.

Competing Interests: No competing interests were disclosed.

\section{I confirm that I have read this submission and believe that I have an appropriate level of expertise to confirm that it is of an acceptable scientific standard.}

Reviewer Report 09 October 2015

https://doi.org/10.5256/f1000research.7372.r10747

(c) 2015 Vanduffel W. This is an open access peer review report distributed under the terms of the Creative Commons Attribution License, which permits unrestricted use, distribution, and reproduction in any medium, provided the original work is properly cited.

\section{Wim Vanduffel}

Athinoula A. Martinos Center for Biomedical Imaging, Massachusetts General Hospital, Charlestown, MA, USA 
This is a very well-written review aimed to provide mechanistic explanations for different variants of perceptual learning (PL). I enjoyed reading the manuscript and am inclined to follow the logic of the authors although a bit more data confirming the conjectures made by the authors would be desirable. The authors first review a number of papers from their laboratory that showed evidence for task-irrelevant perceptual learning. As opposed to more traditional forms of task-relevant PL, task-irrelevant PL occurs in the absence of attention and is supposed to be driven by external or internal rewards. Based on their data, the authors suggest the existence of two mechanisms giving rise to perceptual learning: an automatic reward-driven and a top-down goal-directed one. The studies listed in the review also suggest an interesting and common mechanism shared between conditioning and task-irrelevant perceptual learning.

I only have a number of suggestions that the authors may take into account to improve the manuscript.

1. The authors attempt to dichotomize mechanisms underlying task-relevant vs task irrelevant PL. Are these two parallel systems? Is it possible that only one mechanism exists which can be 'adjusted' based on task constraints? In other words, have they considered only one basic principle, whereby goal-directed PL is simply a variant of task-irrelevant PL? For example, one could argue that rewards are the driving force for perceptual learning dependent plasticity and that additional higher cognitive signals such as selective attention strengthen (or override) the reward-driven changes?

2. Given the fact that the authors promote two different mechanisms, it would be interesting if they can speculate about the neuronal pathways involved.

3. What should be done next? Are additional experimental demonstrations for task-irrelevant perceptual learning required? At this moment a rather limited set of stimulus parameters have been used in task-irrelevant PL paradigms. Does one need additional tests, for example by using other stimulus features, other sensory modalities? What about comparative experiments including other species? What about causal experiments trying to identify structures driving PL-dependent plasticity?

Competing Interests: No competing interests were disclosed.

I confirm that I have read this submission and believe that I have an appropriate level of expertise to confirm that it is of an acceptable scientific standard. 
The benefits of publishing with F1000Research:

- Your article is published within days, with no editorial bias

- You can publish traditional articles, null/negative results, case reports, data notes and more

- The peer review process is transparent and collaborative

- Your article is indexed in PubMed after passing peer review

- Dedicated customer support at every stage

For pre-submission enquiries, contact research@f1000.com 